\title{
TFEB Gene Translocation
}

National Cancer Institute

\section{Source}

National Cancer Institute. TFEB Gene Translocation. NCI Thesaurus. Code C153273.

A cytogenetic abnormality that refers to a translocation involving the TFEB gene. 